\title{
LAS REPRESENTACIONES SOCIALES DE LOS EMIGRANTES ECUATORIANOS EN ESPAÑ̃ SOBRE EL PROCESO MIGRATORIO
}

\author{
GABRIELA MONTERO \\ CESPLA, Universidad de Cuenca (Ecuador).
}

\section{RESUMEN}

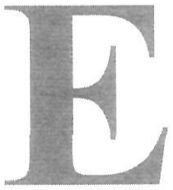

sta investigación pretende explorar las representaciones sociales sobre la migración a España a partir de los relatos que los emigrantes ecuatorianos y sus familias construyen, quienes expresan la manera como se percibe e interpreta la migración desde la visión de su mundo subjetivo. La información que se intercambia en el entorno social sobre las experiencias del proceso migratorio crea imágenes, ya sean positivas o negativas, que alimentan la construcción de las representaciones sociales.

Palabras clave: representaciones sociales, redes migratorias, Ecuador.

\section{INTRODUCCIÓN}

Denise Jodelet considera a las representaciones sociales como el conocimiento práctico que da sentido a los acontecimientos y a los actos que terminan por sernos habituales, participando así en la construcción de nuestra realidad. En este sentido, el mundo subjetivo de los emigrantes y sus familias, sumado a factores externos, como los medios de comunicación, conocimientos, modelos de pensamiento, ideologías, acontecimientos que se presentan en nuestro medio, influyen en la reproducción de la migración, a la vez que permiten la creación de representaciones sociales.

Este estudio se presenta en cuatro temas que permiten explicar la influencia de las representaciones sociales en la reproducción de la emigración de ecuatorianos a España: a) el papel que juegan los imaginarios sobre el país de destino, creados por los inmigrantes ecuatorianos, las familias en el país de origen, los medios de comunicación y la sobrevaloración e imitación de todo lo que proviene de los países del centro; b) la importancia de las redes sociales para el intercambio de información que reproduce el proceso migratorio; c) la conformación de la imagen del inmigrante triunfador para alimentar el "sueño europeo" y d) la relación entre las representaciones que se construyen sobre España y Estados Unidos en el Ecuador. 
Este trabajo persigue los siguientes objetivos:

- Objetivo general. Conocer si las representaciones sociales y los imaginarios influyen en el proceso migratorio para fomentar y reproducir la emigración de ecuatorianos a España.

- Objetivos específicos.

- Señalar la influencia de las redes de familiares y de amigos para la construcción del imaginario colectivo que se percibe en el país de origen y reproduce la emigración.

- Identificar si las representaciones sociales sobre España, construidas en el país de origen, coinciden con las representaciones que se conciben sobre los Estados Unidos para fomentar la decisión de emigrar.

En cuanto a la metodología, el presente estudio utiliza las técnicas de investigación cualitativa como la entrevista a profundidad y los relatos cruzados, que permiten en la investigación de campo integrar los relatos de los familiares de emigrantes en Ecuador con los relatos de los emigrantes en España. Se realizaron un total de cuarenta entrevistas: veinte dirigidas a familias de inmigrantes en Ecuador y veinte a inmigrantes en España. La selección de las personas entrevistadas responde a criterios de representatividad cualitativa: profesión, instrucción, tiempo de permanencia, ocupación en el país de destino, antigüedad de la migración, entre otras características. En Ecuador, la muestra fue tomada únicamente en la zona sur de la sierra ecuatoriana, en las provincias de Azuay, Cañar y Loja y en el caso de España en Madrid, Murcia, Barcelona y Alicante.

\section{CONTEXTO DE LA MIGRACIÓN ECUATORIANA}

Las migraciones internacionales han cobrado mayor fuerza en las últimas décadas a raíz de las diversas transformaciones suscitadas por los cambios económicos, tecnológicos y sociales que se generan como producto de la globalización. La globalización de la economía ha propiciado que la brecha de las desigualdades entre los países del centro y de la periferia se extienda sin control, conduciendo a la producción y la ubicación de la riqueza en pocos Estados y al deterioro de las condiciones de vida de la mayoría de la población mundial, sumado a una serie de problemas coyunturales por los que atraviesan los Estados pobres.

En el caso del Ecuador, el fenómeno migratorio no responde a un hecho reciente; los desplazamientos más antiguos se remontan a la década de los años cincuenta, los mismos que se inician en las provincias de Azuay y Cañar, debido a la caída de la exportación de los sombreros de paja toquilla, teniendo como destino los Estados Unidos.

La emigración masiva de ecuatorianos se inicia a partir de la última década del siglo XX, intensificándose a finales de los años noventa. Son varias las causas que detonaron este proceso, siendo la principal la crisis económica, a la que se suma la inestabilidad política y una serie de factores coyunturales que potenciaron los problemas. "El Ecuador experimentó el empobrecimiento más acelerado en la historia de América Latina. Entre el año 1995 y el año 2000, 
el número de pobres creció de 3,9 a 9,1 millones, en términos porcentuales de 34\% al 71\%; la pobreza extrema dobló su número de 2,1 a 4,5 millones" (Acosta, 2003; 56).

Según datos proporcionados por el Instituto Nacional de Estadísticas y Censos, los destinos claves de la emigración ecuatoriana se concentraron en países como Estados Unidos, España e Italia. Sorpresivamente, a partir del año 1999, España se convierte en el destino más atractivo para los/as ecuatorianos/as, quienes consideran la opción de emigrar como una estrategia que busca mejorar sus condiciones de vida y las de sus familiares. Para contar con una idea sobre el número de ecuatorianos/as que viven en España, el Instituto Nacional de Estadística -INE- y el Padrón Municipal de habitantes de ese país demostraron que, en el año 2003, Ecuador se encontraba en el primer puesto de las nacionalidades de población inmigrante empadronada con un total de 390.000 personas, datos que dejan de lado a un considerable número de inmigrantes que se encuentran en una situación vulnerable al permanecer en condición de irregulares.

Así, podemos anotar que la emigración ecuatoriana a España se caracteriza por ser un fenómeno reciente y masivo, donde obviamente se ha reproducido por la inexistencia de un visado para viajar (el visado para ecuatorianos entró en vigencia en agosto de 2003) y la facilidad por el uso del mismo idioma castellano, sumado al desarrollo de la tecnología en las telecomunicaciones y el transporte, que han influido y facilitado para que este flujo continúe reproduciéndose en tales magnitudes. A este aspecto, se suma también la decisión propia del emigrante para realizar el viaje, la misma que está condicionada por la presencia de las representaciones sociales que se construyen sobre el lugar de destino desde Ecuador. De igual manera, las redes de familiares y de amigos, tanto en el país de origen como en el de destino, agilizan y reproducen el proceso migratorio al intercambiar información para construir representaciones: crear el imaginario del país de destino como el lugar idóneo para cumplir sus aspiraciones personales y las de sus familiares, incentivar e invitar a realizar el viaje, préstamo de dinero para pagar el mismo, facilitar el acceso a la vivienda, al trabajo y a la inserción misma en el país de destino, es decir, llegan a crear una especie de institución de soporte y solidaridad para los nuevos inmigrantes.

Otro aspecto que merece atención es la antigua presencia de la migración de las provincias de Azuay y Cañar hacia los Estados Unidos. Como se anotó anteriormente, esta migración empezó hace varias décadas, por lo tanto, son visibles los resultados que ha generado, en el sentido de que se puede evidenciar el destino de las remesas en la adquisición de bienes materiales, como casas, edificios, terrenos, vehículos. Las representaciones sociales y los imaginarios que se han construido en el país de origen corresponden al éxito y bienestar que la migración puede generar, y que es palpable ante la materialización de los bienes antes mencionados. Estas representaciones e imaginarios están también presentes en el caso de España, aunque la emigración hacia este país sea reciente, por lo que todavía no son muchos los casos visibles en cuanto a la adquisición de bienes materiales por el efecto de las remesas, si comparamos con el caso de los Estados Unidos. 


\section{ENFOQUES TEÓRICOS}

Las representaciones sociales han sido abordadas por diferentes disciplinas dentro de las ciencias sociales, sin embargo, en la psicología social, se han dado las principales aportaciones teóricas. Denise Jodelet considera a las representaciones sociales como "el conocimiento de sentido común o bien pensamiento natural, por oposición al pensamiento cientifico que se construye a partir de nuestras experiencias, pero también de las informaciones, conocimientos $y$ modelos de pensamiento que recibimos y transmitimos a través de la tradición, la educación y la comunicación social: un conocimiento socialmente elaborado y compartido" (Moscovici, 1988; 473).

Pueden ser definidas, entonces, como la manera en que los individuos de un contexto social conciben e interpretan la realidad a través de su interacción dentro del mismo contexto. Jodelet también sostiene que las representaciones, como su nombre indica, son la representación mental de algo -objeto, idea, persona, acontecimiento- siendo ésta la razón de su parentesco con los símbolos, signos, ya que permiten a este contenido mental restituir de modo simbólico algo ausente. A esta acción de reproducir, se suman también las acciones de construir y crear individual y colectivamente, al permitir que la representación mental tenga su parte de interpretación.

Robert Farr señala la función doble de las representaciones sociales: "primero, establecer un orden que permita a los individuos orientarse en su mundo material y social y dominarlo; segundo, posibilitar la comunicación entre los miembros de una comunidad proporcionándoles un código para el intercambio social y un código para nombrar y clasificar sin ambigüedades los diversos aspectos de su mundo y de su historia individual y grupal" (Mora, 1992).

Las representaciones sociales que se construyen sobre la migración pertenecen a una realidad concreta que se inserta dentro de un contexto a partir de las experiencias y vivencias de un grupo socio-cultural, donde la presencia de elementos subjetivos - sentimientos, motivaciones, expectativas-influye sobre sus comportamientos y en la toma de decisiones. Al respecto, se sostiene que "un aspecto novedoso que se desprende dentro de esta racionalidad que justifica la decisión migratoria es que la misma se inscribe dentro de un campo ideal. Es el campo de la ilusión. Esta ilusión está inmersa en el mundo interior, el mundo de la subjetividad, en la esperanza de que la migración se constituya en un potencial que permita enfrentar la realidad y auto proyectarse" (Goycoechea, 2003; 35).

\section{REPRESENTACIONES SOCIALES E IMAGINARIOS SOBRE EL PAÍS DE DESTINO}

Teófilo Altamirano, antropólogo peruano, señala que la migración internacional no debe ser vista sólo como un proceso poblacional y económico sino como un proceso cultural. Dentro de este proceso cultural, se verá la migración como un "modelo a imitar" que inevitablemente influirá en el momento de la toma de decisión para poner en marcha el proyecto migratorio. A situaciones como éstas, se suma la poca difusión de los elementos culturales de los países 
subdesarrollados y la mayor difusión de las culturas que se han convertido en culturas dominantes, por el nivel de desarrollo alcanzado, bienestar, estilos y formas de vida, asociado a la imagen de modernidad. Estos hechos contribuyen a que la población llegue a sobrevalorar aquello que no es propio y se construya en el imaginario colectivo la idea positiva del país que será el lugar de destino final. Se insiste en denominar a esta situación de anhelo por llegar a estos países como "el sueño americano o el sueño europeo", definiéndolo como: "un estado mental resultante de las supuestas comodidades materiales, mejores niveles de vida, de las imágenes positivas que se tiene de Europa" (Altamirano, 1996).

En esta investigación, la imagen positiva del país de destino se manifiesta a través de las motivaciones y aspiraciones económicas y personales que los emigrantes ecuatorianos poseen y que están seguros que en él podrán alcanzar. Cabe recalcar que la representación social que construyen sobre la emigración a España en el lugar de origen se refiere concretamente a un país que ofrece una sólida economía, el lugar idóneo, ideal que proporciona mayores oportunidades en todos los ámbitos, especialmente en el laboral, para mejorar las condiciones de vida de los emigrantes y sus familiares. Esta sobrevaloración del lugar de destino presenta, al mismo tiempo, una visión pesimista o negativa de Ecuador, especialmente al hablar sobre la situación socio-económica y política del país.

"Vine por la economía, porque nuestro país está lleno de corrupción, las leyes son más rectas acá que en Ecuador y a los más pobres nos friegan, y entonces qué pasa cuando uno siente ya el golpe: se va para EEUU, viene acá (España) pensando en un futuro mejor".

Testimonio de un emigrante ecuatoriano en Jumilla, Murcia.

"En el país no hay buenas condiciones, los sueldos son bajos y no hay fuentes de trabajo, el gobierno no nos da buenas oportunidades para quedarnos, allá no alcanzaba lo que se ganaba, por eso decidi viajar, para tener un mejor futuro".

Testimonio de un emigrante ecuatoriano en Madrid.

Alba Goycoechea sostiene que la migración se convierte en una oportunidad para concretar ciertas expectativas que son el resultado de una estrategia familiar. Así, de igual manera, la migración puede comprenderse como una ilusión, es decir, "una construcción interna del individuo o auto identificación de carácter proyectivo que expresa un deseo o una motivación asociada al beneficio que esperan" (Goycoechea, 2003; 24). En este sentido, los emigrantes entrevistados y sus familiares conciben la migración como una oportunidad beneficiosa, un anhelo positivo en el sentido económico que permite mejorar sus condiciones de vida mediante el cumplimiento de expectativas concretas vinculadas a la adquisición de ciertos bienes materiales que permitan proyectarse en un futuro mejor.

"Con la migración se puede llegar a tener un mejor futuro, una mejor posición económica; se puede llegar a obtener lo que quieras en el aspecto económico. Aqui se trabaja quince, veinte años y se tiene derecho a la jubilación". Testimonio de un emigrante ecuatoriano en Madrid. 
"Considero a la migración como positiva: se gana bien, se vive bien, hay posibilidad de ahorro y de mejorar las condiciones de vida de la familia". Testrmonio de una Emigrante eCuAtoriana en Barcelona.

Un aspecto importante de abordar la migración dentro de la construcción del imaginario colectivo ecuatoriano es la posición contradictoria que presentan los familiares de los emigrantes sobre el país de destino. Si bien por un lado poseen una imagen positiva del país de destino, construida a partir de los relatos de los propios inmigrantes que se transmiten en la sociedad de origen y de la información favorable que circula en el medio social a través de las redes de familiares y de amigos sobre diferentes aspectos de "bienestar" del lugar de llegada. Por otra parte, los familiares conocen también la realidad que se vive en el país de destino: el sufrimiento ocasionado por la separación familiar, los relatos de la situación de sus familiares en el exterior, quienes enfrentan duras condiciones en el ámbito laboral y de adaptación. A pesar de esta contradicción, los relatos positivos superan a los negativos y las expectativas por emigrar se vuelven costumbre y se intensifican, tal vez, por la ilusión de vivir la experiencia en "carne propia". De esta manera, se construye la representación social sobre la migración en nuestro medio, como la realidad que está presente cotidianamente y es la única que se conoce.

"La migración es buena porque mejoran las condiciones de vida de la familia y pienso que es mala porque se les extraña mucho, trabajan bastante y el trabajo es duro".

TESTIMONIO DE UN FAMILIAR DE EMIGRANTE EN LOJA.

"Mi hermano está bien (España), ya se compró un piso aunque al principio dijo que sufrió bastante. En las fotos se le ve bien contento, nos mandó un video y sé que las cosas son diferentes allá, las casas, el tren, los parques, allá es otro mundo".

Testimonio de una hermana de emigrante en Cuenca.

También, no debe dejarse de lado la influencia que presentan los medios de comunicación (televisión, radio, Internet, diarios, telefonía celular, locutorios) al difundir información favorable sobre el país de destino como punto de atracción. En esta investigación pudimos constatar, al entrevistar a los familiares de emigrantes, que la gran mayoría posee un teléfono celular para comunicarse constantemente con su familia, siendo más común en el caso de los familiares que viven en las zonas rurales de las provincias que están dentro de nuestro estudio. En este sentido, la telefonía celular se convierte en una herramienta indispensable que facilita la comunicación permanente entre las familias. También es evidente en estas tres provincias - Azuay, Cañar y Loja- la proliferación de locutorios y courriers no solamente en las capitales de las mismas sino en los pueblos.

\section{IMAGEN DE LOS EMIGRANTES ECUATORIANOS AL LLE- GAR AL PAÍS DE DESTINO}

Es indispensable destacar también la imagen que poseen los emigrantes ecuatorianos al llegar al país de destino para constatar si corresponde con la 
misma que tenían en el país de origen. En este sentido, los emigrantes entrevistados concuerdan que la imagen positiva que tenían en un principio sobre España cambia al momento de llegar, por las situaciones difíciles que deben afrontar por su condición de emigrante. Primero debemos ubicar el choque cultural y la inseguridad que enfrentan, sobre todo cuando tienen que adoptar nuevas formas de vida, como compartir la vivienda con personas extrañas, lo que conlleva dejar de disponer de sus propios espacios por lo caro que resulta el alquiler.

"Me fui a vivir donde mis primos pero cuando yo llegué era impactante, como todo el mundo viene aqui y se encuentra con el cuadro de un montón de personas con poco espacio, de que no conoces a nadie ni sus costumbres". Testimonio de una emigrante en MadriI.

Los nuevos códigos culturales, las condiciones físicas que presentan las grandes ciudades con sus servicios, que se muestran extraños e innovadores, como el uso del tren, producen reacciones de asombro e incluso temor, sobre todo a su llegada. A esto, se suman las duras condiciones que soportan, especialmente quienes trabajan en la agricultura -horarios de trabajo agotadores, condiciones climáticas extremas que pueden ocasionar problemas de salud, situaciones de explotación en el trato y salarios bajos-. En el caso de las mujeres que trabajan como internas manifiestan la soledad debido al encierro obligatorio que les exige esta condición, la separación de su familia, horarios de trabajo agotadores, sueldos bajos, etc. A esta inestabilidad, le sigue la preocupación por pagar la deuda adquirida por el viaje y empezar a enviar dinero para la manutención de la familia, educación de los hijos o la construcción de una casa.

"Cuando llegué a España me di cuenta de que la realidad era otra, el dia que no trabajas padeces, pasas hambre".

TESTIMONIO de UN EMIGRANTE ECUATORIANO EN JUMILLA.

"Vine pensando en un futuro mejor, uno llegando acá se da cuenta de que es todo lo contrario”. Testimonio de una emigrante eCuatoriana en MadRid.

Las duras condiciones de adaptación al nuevo entorno continúan presentes en el proceso migratorio, incluso persisten en la etapa de inserción. El choque cultural al que hacemos referencia se ve reforzado en el caso de aquellas personas que, teniendo estudios superiores, tienen que trabajar en empleos que no requieren calificación alguna, provocando situaciones de frustración que constantemente son manifestadas.

"Mi hermana no me dijo cómo son las cosas aquí en realidad, ni las posibilidades que tenía. Ella me dijo que iba a estar muy bien aquí (Madrid). Yo trabajaba de auxiliar de contabilidad allá y entonces ella me decía que iba a ganar bien aqui, pero nunca me dijo que iba a trabajar de interna". TeSTIMONIO DE UNA EMIGRANTE ECUATORIANA I:N MADRID.

"Es dificil aceptar que trabajo de interna cuando en Ecuador tenía un trabajo de escritorio. Cuando trabajas en algo que no te gusta se vuelve pesado, si trabajas en algo que a ti te gusta, no te importa quedarte si son doce, trece o catorce horas, pero en cambio estás haciendo el trabajo que a ti te gusta. Es duro adaptarte a un trabajo para el que no 
se requiere calificación, después de venir de un medio en donde estudié

una carrera". TESTIMONIO DE UNA EMIGRANTE ECUATORIANA EN BARCELONA.

Con el paso del tiempo, intentan ubicarse en trabajos que están relacionados con sus profesiones, no todos lo consiguen, ya que se presentan obstáculos como la dificultad para homologar sus títulos universitarios. El proceso lleva años para conseguir la tramitación. Cuando, al fin, logran ubicarse en estos trabajos, se produce una gran satisfacción, a pesar de no recibir buenas remuneraciones y tener que trabajar horas extras en otros sitios. Llama la atención durante las entrevistas ver cómo aquellos emigrantes que son profesionales tienden a dar a conocer los estudios que poseen y la actividad que realizaban en Ecuador. Esto demuestra la situación de insatisfacción personal en la que se encuentran, y a ello se suma su interés por seguir capacitándose para conseguir mejores oportunidades en España. Estos deseos se materializan cuando asisten a cursos organizados por los ayuntamientos, ONGs, Cruz Roja u organizaciones de la Iglesia.

"Empecé a estudiar un diplomado en Intervención Socio-sanitaria, así lo llaman aqui para las personas mayores y discapacitadas. Esto lo consegui también a través de las $O N G$ s, lo que suele salir con los convenios de la Cruz Roja y del Fondo Económico de la Comunidad Europea, que facilitan a personas migrantes a mejorar sus empleos".

Testimonio de una emigrante ecuatoriana en Madrid.

"Antes trabajaba de interna y con eso pagaba mis estudios, la alimentación y el transporte. Me preocupa no poder homologar mi título de Enfermería aún, creo que asi tendria mejores oportunidades de trabajo. Quiero trabajar en algo que se relacione con mi profesión. Ahora cuido ancianos por horas en una residencia para mayores, trabajo siete horas al dia en diferentes horarios. Gano casi 700 euros, a veces también cuido niños y gano dinero extra".

TESTIMONIO de UnA EMIGRANTE ECUATORIANA EN MADRID.

En el caso de las mujeres ecuatorianas, el principal problema que señalan es la desintegración familiar, a causa del sufrimiento que representa estar lejos de sus familiares, especialmente para las madres, quienes temen perder el cariño de sus hijos. La separación de su medio cultural, de sus costumbres también afecta en este sentido.

"Yo no me enseño, lo que pasa es que estoy acostumbrada al trabajito, pero sin mis hijos aquí no soy nadie. Me quedo un año más y luego me regreso, mire que me he perdido muchas cosas de ellos, no los he visto crecer, ya están jovencitos".

TESIMMONIO DE UNA EMIGRANTE ECUATORIANA EN BARCELONA.

Las percepciones sobre el lugar de destino que los emigrantes ecuatorianos construyen están presentes dentro de las representaciones sociales. De esta manera, al hablar sobre lo que la migración representa para ellos, se desprenden oportunidades y problemas, siendo las percepciones negativas las que tienen mayor peso, como anotamos anteriormente al hablar de la desintegración familiar, el choque cultural, la dificultad para insertarse en el ámbito laboral, así como la condición de irregularidad, la discriminación, entre otros problemas. 
Cuando los emigrantes hacen referencia a las percepciones positivas, la respuesta siempre es la misma, al estar de acuerdo en que la migración es una oportunidad beneficiosa en el sentido económico al permitir mejorar su condición de vida. En este sentido, el envío de las remesas permite satisfacer ciertas expectativas vinculadas a la adquisición de bienes materiales, al pago de la educación de sus familiares o a sustentar los gastos domésticos una vez que se concluya el pago de la deuda adquirida como consecuencia del viaje.

"Veo a la migración como positiva y negativa. Positiva, si vienes y cumples los sueños y metas que te propusiste. Y negativa, cuando vienes y te pasas diez años y no sabes qué hacer: si regresarte, si quedarte, te has gastado todo el dinero, no has cumplido tus metas y te has alejado de tus hijos". Testimonio de un emigrante ecuatoriano en Madrid.

\section{LA INFLUENCIA DE LAS REDES SOCIALES.}

Otro aspecto importante dentro de la construcción del imaginario sobre la migración es el papel que cumplen las redes de familiares y amigos en el intercambio de la información para fomentar y reproducir la emigración. Al respecto, se señala: "el establecimiento de redes da lugar al efecto dominó, es decir la reacción social en cadena que opera bajo mecanismos de imitación colectiva, lo cual es un factor de atracción de la migración que opera fundamentalmente a través de los lazos familiares. Su papel fundamental es, por un lado, reproducir en el lugar de destino formas de organización social y de comportamiento cultural como estrategias de adaptación del migrante $y$, por otro, mantener una red de comunicación permanente con el lugar de origen y alcanzar así una relación de identidad y pertenencia relativamente impermeable al desarraigo" (Carpio, 1992; 80).

"Mi esposo me trajo a este lugar, él vino un año antes acá donde unos primos, ellos le ayudaron a conseguir trabajo en el campo, reunió el dinero y me mandó para el pasaje. Su familia aquí es numerosa, entre todos alquilamos un lugar donde nos reunimos los domingos a escuchar el Evangelio y alabar a nuestro Señor".

Testimonio de una emigrante ecuatoriana en San Cayetano, Murcia.

En el caso de los ecuatorianos, las redes juegan un papel primordial desde el momento en que se concibe la idea de viajar. La información que circula en el medio social sobre el país de destino y sobre las experiencias y vivencias de los inmigrantes está presente en la cotidianidad, al mismo tiempo que alientan a otros a tomar la decisión de viajar. Las redes empiezan a operar a través de sus múltiples mecanismos al proveer la información y los medios para la preparación del viaje, préstamo de dinero a través de familiares o usureros, arreglo de documentos y pasajes en una agencia de viajes confiable, asesoría sobre el viaje. En cuanto a la llegada en el país de destino, las redes tienen acceso a la vivienda, al mercado de trabajo, al contacto con otros ecuatorianos al acceder a lugares que son su punto de encuentro social, a la información sobre el lugar de llegada para que el inmigrante pueda insertarse en un inicio en el país de acogida. 
"Vine a España en el año 1999, llegué donde unos amigos en San Javier (Murcia), ellos me dijeron que venga y me orientaron cuando llegué. Me ayudaron también con la vivienda y la alimentación, luego le traje a mi esposa." Testimonio de un emigrante ecuatoriano en Jumilla, Murcia.

Es necesario considerar también que los relatos favorables sobre la situación beneficiosa en la que se encuentran los inmigrantes ecuatorianos crean expectativas entre sus familiares y amigos, permitiendo intercambiar en el medio social sus experiencias que fomentan y alimentan la emigración, convirtiéndose en un modelo de imitación. A esto, se suma el carácter económico de la migración, con el envío de las remesas y su utilización en la adquisición de bienes materiales, como casas, terrenos, vehículos, bienes que jamás podrían ser adquiridos con los ingresos que se obtienen en el país de origen. Esta evidencia material que está a la vista de todos construye la imagen positiva de la migración como respuesta a la crisis económica que se vive en el Ecuador.

"Los culpables somos los ecuatorianos porque cuando llaman a sus familias dicen que ganan tanto, que es una maravilla estar en España, entonces en Ecuador se meten eso en la cabeza y piensan que acá se gana bien. La conversación de la gente de aqui es mentira, dicen que ganan bien y la gente de allá por eso quiere viajar".

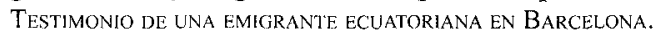

En este estudio, la mayoría de emigrantes ecuatorianos, al comunicarse con sus familiares, presentan una imagen exitosa que pretende no causar preocupaciones, prefieren seguir manteniendo el discurso positivo de que todo está muy bien, aunque estén enfrentando en realidad situaciones difíciles.

"Alrededor de la figura del emigrante se ha creado una cierta imagen mitificadora, ya que éste ha pasado de representar la figura del pobre, del excluido, a asumir riesgos y atributos del héroe dispuesto a afrontar riesgos como privaciones y renuncias por alcanzar un ideal" (Fundación ETNOR, 2002; 63).

"Nosotros nunca podemos hacer sufrir a la familia. Yo, por ejemplo, soy capaz de luchar, pero nunca darles motivos a que sufra mi familia, uno les dice que está bien y al mismo tiempo le están saliendo las lágrimas. Es que uno en la distancia trata por todos los medios de no perjudicarlos sentimentalmente".

Testimonio de un emigrante ecuatoriano en Jumilla, Murcia.

\section{LA REPRESENTACIÓN DEL INMIGRANTE QUE NO FRA- CASA (EL TRIUNFADOR)}

Los emigrantes ecuatorianos expresan los planes y proyectos que llevan al país de destino, sumados a la imagen positiva que tienen de España, los mismos que están cargados de componentes idealizadores de la realidad que encuentran. Sienten inseguridad al enfrentarse con nuevos cambios, pero deciden continuar con sus planes, aunque en la mayoría de los casos las difíciles situaciones que viven les sugieran la necesidad de regresar. No pueden concebir dentro de su proyecto migratorio el hecho de regresar al Ecuador como "un fracasado", ya que la imagen que tienen en el pais de origen sobre el inmigran- 
te que retorna luego de algún tiempo es de éxito y poseedor de bienes y dinero. El retorno inmediato estaría asociado al fracaso.

Cuando llegan al país de destino se puede identificar tres momentos.

\subsection{Los recién llegados.}

Todos concuerdan en que el cambio que implica emigrar provoca un choque cultural, sumado al sufrimiento que significa dejar a su familia en el lugar de origen. Todo este cambio les sugiere la necesidad de regresar, al mismo tiempo que se contrapone la imagen de no ser un fracasado. Este término tiene implicaciones como ser mal visto por regresar sin ahorros o sin haber obtenido beneficios materiales visibles como la construcción de una casa, la compra de un terreno o un vehículo, por ejemplo. A todo esto, se suma, como otro obstáculo, el pago de la deuda que adquirió.

"Mi hermana me decía: y tú vas a volvery ¿qué te van a decir? que has fracasado y has vuelto. También eso te hace pensar y dices bueno por qué voy a volver". Testimonio de UNA EMIGRANTE ECUATORIANA.

"Yo decía: a los 3 meses pago la deuda y me vuelvo, que va, imposible, te surgen otros problemas, cosas o ya intentas ayudar a tu familia y te vas quedando". TESTIMONio de una EMIGRANTE ECUATORIANA.

\subsection{Los que están dos o tres años}

Una vez que han pasado por el cambio, han sufrido en el proceso, han conseguido regularizarse en la mayoría de los casos y han logrado pagar la deuda, sienten la necesidad de regresar, pero se dan cuenta de que no pueden hacerlo porque todavía no han ahorrado dinero suficiente para construir una casa, abrir un negocio o mantener a su familia. De igual manera, piensan que, si retornan, serán considerados como fracasados. Prefieren no causar sufrimiento ni preocupaciones a sus familiares y decirles que se encuentran bien, aunque no sea cierto.

"No quisiera regresar y que todos me digan: este hombre estaba tantos años en España y ¿qué ha hecho? Pero tampoco quiero que me vean como el fracasado". Testimonio dE UN EMIGRANTE ECUATORIANO.

\subsection{Los que están cuatro, seis o más años}

Envían remesas mensualmente, han empezado a ahorrar, la mayoría ha comprado un terreno, ha empezado a construir una casa, pero no se sienten conformes con lo que han alcanzado para regresar. La mayoría sostienen que el salario que ganan apenas les permite ahorrar, a la vez que destinan parte del mismo para el envío mensual de remesas. La idea del retorno está presente pero a largo plazo. Algunos han regresado a Ecuador en una o dos ocasiones, están concientes del gasto que implica el viaje y son vistos ante sus familiares y amigos como el emigrante triunfador, que gana mucho dinero. Afirman que tienen que llevar una considerable suma de dinero para costear invitaciones, hacer gastos, etc. 
"Me fui a Ecuador y vine gastando mucho dinero, me hubiese ido a cualquier otro país del mundo con menos dinero del que llevé a Ecuador porque allá están los compromisos con la familia, aparte de todos los regalos que tienes que llevar y de que te vean como el extranjero que llega con divisas. Ellos no saben si a lo mejor han ido cinco o seis años de ahorro, o a lo mejor te endeudaste para llevar todo ese dinero".

Testimonio de una emigrante ecuatoriana en Madrid.

\section{VIII.LA REPRESENTACIÓN SOCIAL SOBRE LA MIGRACIÓN A LOS ESTADOS UNIDOS}

Han transcurrido varias décadas desde los años 50-60 donde surgieron los primeros brotes migratorios hacia los Estados Unidos desde las provincias de Azuay y Cañar. Durante este tiempo, diversos grupos migratorios se han concentrado en ese país, albergando a un flujo masivo de emigrantes ecuatorianos. En nuestro país, encontramos las evidencias materiales de todo este proceso, fruto de las remesas, así como los relatos sobre las experiencias de generaciones de emigrantes, los cuales han contribuido a crear la representación social de la migración hacia los Estados Unidos como el país que ofrece las mejores oportunidades para adquirir una serie de beneficios económicos que permiten mejorar las condiciones de vida de las familias ecuatorianas. A este aspecto, se agrega,"la penetración económica, política y militar de Estados Unidos en América Latina, la cual está acompañada y legitimada por las influencias culturales que son, aparentemente, más dominantes, como el cine, la televisión $y$ otras formas mediáticas de penetración en el mundo postcolonial "(Pedone, 2002; 59). En efecto, la presencia del "sueño americano" contribuye a la creación del imaginario sobre las virtudes y beneficios que ofrece este país del norte, para fomentar y reproducir la emigración de ecuatorianos al exterior.

En esta investigación, los ecuatorianos entrevistados piensan como primera opción al momento de emigrar en los Estados Unidos, concebido como el país que ofrece mayores ventajas económicas en cuanto a mejores salarios en comparación con los que reciben en España, y facilidades para trabajar en lo que respecta al acceso de empleos sin importar la condición de irregular del emigrante; razones que se evidencian con la presencia de numerosos bienes materiales en nuestro medio, como un símbolo de prosperidad económica y éxito.

"Mi hermana piensa ir a Estados Unidos porque allá se trabaja duro pero se gana más que en España".

Testimonio de una hiJa de EMIGRANTE ECUatoriano en CAÑar.

"No tenía ninguna idea antes de llegar de cómo era España. Dicen que en Estados Unidos se gana mejor y hay más trabajo para los que no tienen papeles, pero se sufre más en el camino".

Testimonio de un emigrante ecuatoriano en Alicante.

La respuesta al cambio de destino como parte del proyecto migratorio de los ecuatorianos a España a partir de la década de los 90 , responde a factores externos, como la presencia de políticas migratorias más restrictivas por parte 
del gobierno estadounidense, los altos costos de endeudamiento para financiar el viaje (fluctúan entre 8.000 y 12.000 dólares), la alta demanda de mano de obra inmigrante por parte de España en determinados sectores laborales, la inexistencia de un visado que entró en vigencia en agosto de 2003 o la utilización del idioma castellano. Estados Unidos y España se han consolidado como países de destino claves para la emigración de ecuatorianos al exterior, al presentarse como los lugares idóneos para alcanzar las aspiraciones económicas y materiales, producto del imaginario construido por el sueño americano y europeo.

\section{CONCLUSIONES}

Las representaciones sociales ayudan a comprender el estudio de las migraciones desde otro enfoque al permitir adentrarse en el mundo subjetivo de los actores sociales para poder conocer sus expectativas, anhelos y motivaciones que se presentan en la realidad cotidiana como consecuencia del abandono del lugar de origen hacia otros destinos.

Las representaciones sociales sobre la migración a España se construyen a partir de las expectativas de los ecuatorianos que están latentes en la cotidianidad y donde también figura la imagen positiva del país de destino para sobrevalorar las condiciones de desarrollo y bienestar que presenta. La migración es concebida como la oportunidad para cumplir las expectativas y anhelos del grupo familiar - considerado como su unidad ejecutora--, al permitir la mejora de sus condiciones de vida como respuesta a la crisis económica que el país ha atravesado en los últimos tiempos.

Es importante también resaltar el papel que cumplen las redes de familiares y amigos para reproducir la migración. La información que circula dentro de ellas, con los relatos favorables de los emigrantes, la difusión de los medios de comunicación y la utilización de las remesas, alimenta la ilusión del viaje. No podemos dejar tampoco de lado la imagen que se construye sobre la migración a partir de las experiencias de los propios emigrantes para comprender el proceso migratorio en casi su totalidad.

\section{BIBLIOGRAFÍA}

ACOSTA A., LOPEZ S. [et al]. La emigración vista desde la crisis y la dolarización. Revista Fe y Justicia de la Compañía de Jesús. Volumen $\mathrm{N}^{\circ}$ 9. Quito. 2003.

ALTAMIRANO, T. Migración: el fenómeno del siglo. Lima. PUCP, Fondo Editorial. 1996.

CARPIO, P. Entre pueblos y metrópolis. Quito, Ediciones Abya-Yala/ILDIS. 1992.

Diccionario Crítico de Ciencias Sociales. Representaciones Sociales. Disponible en www.ucm. es/info/eurotheo/diccionario/R/representaciones_sociales.htm/

Fundación ETNOR. Aspectos claves de la inmigración. España. 2002.

GOYCOECHEA, A. Los imaginarios migratorios. Quito. Ediciones Abya-Yala. 2003.

MANZANOS, C. El grito del otro: arqueologia de la migración racial. Madrid. Editorial Tecnos. 1999. 
MOSCOVICI, S. Psicologia Social II. Pensamiento y vida social. Psicología social y problemas sociales. Barcelona. Paidós. 1988.

MORA, M. El modelo de las representaciones sociales de Serge Moscovici. Universidad de Guadalajara. 1992. Disponible en www.geocities.com/Paris/Rue/8759/moscoini.html/

PEDONE, C. Las representaciones sociales en torno a la inmigración ecuatoriana en España. Revista de FLACSO ICONOS. N.14. Quito. 2002.

YANEZ COSSIO, C. Representaciones y conceptos estructurantes. Quito. Ediciones Abya-Yala. 1990. 